\title{
Hubungan Faktor Risiko Kegawatdaruratan Obstetri Menurut Rochjati dengan Pelaksanaan Rujukan oleh Bidan di RSUD Gambiran Kediri
}

\author{
Fauzia Laili, ${ }^{1}$ Herry Garna, ${ }^{2}$ Gaga Irawan, ${ }^{3}$ Farid Husin, ${ }^{4}$ Firman F.Wirakusumah, ${ }^{5}$ Deni K.Sanjaya, ${ }^{6}$ Hadi $S^{7}$ \\ ${ }^{1}$ Mahasiswa Program Studi Magister Kebidanan Fakultas Kedokteran Universitas Padjadjaran \\ ${ }^{2}$ Departemen Ilmu Kesehatan Anak Fakultas Kedokteran Universitas Padjadjaran \\ ${ }^{3}$ Departemen Ilmu Gizi Fakultas Kedokteran Universitas Padjadjaran \\ ${ }^{4}$ Departemen Epidemiologi dan Biostatistika Fakultas Kedokteran Universitas Padjadjaran \\ ${ }^{5,7}$ Departemen Obstetri dan Ginekologi Fakultas Kedokteran Universitas Padjadjaran \\ ${ }^{6}$ Departemen Ilmu Kesehatan Masyarakat Fakultas Kedokteran Universitas Padjajaran
}

\begin{abstract}
Abstrak
Kegawatdaruratan obstetri merupakan penyebab utama kematian maternal dan perinatal. Kegawatdaruratan obstetri menurut Rochjati terbagi menjadi 3 kelompok faktor risiko, yaitu APGO (Ada Potensi Gawat Obstetri), AGO (Ada Gawat Obstetri), dan AGDO (Ada Gawat Darurat Obstetri). Berbagai penelitian menyatakan salah satu upaya penatalaksanaan yang efektif pada kegawatdaruratan obstetri dengan pelaksanaan rujukan. Rujukan yang tepat dan terencana dapat menyelamatkan ibu dan bayi baru lahir. Penelitian ini bertujuan untuk mengetahui hubungan faktor risiko kegawatdaruratan obstetri (APGO, AGO, dan AGDO) dengan pelaksanaan rujukan oleh bidan di RSUD Gambiran Kediri. Desain penelitian secara kuantitatif dengan pendekatan potong silang dilaksanakan pada Januari-Februari 2014 dengan jumlah sampel sebesar 150. Pengambilan sampel dilakukan dengan cara consecutive sampling. Pengumpulan data sekunder berdasarkan laporan ruang bersalin dan rekam medik rumah sakit periode Januari-Desember 2011. Hasil penelitian menunjukkan tidak terdapat perbedaan bermakna faktor risiko kegawatdaruratan obstetri pada variabel APGO dan AGO antara rujukan terencana dan rujukan terlambat $(\mathrm{p}>0,05)$, namun terdapat perbedaan bermakna pada variabel AGDO antara rujukan terencana dan rujukan terlambat. Meningkatnya faktor risiko kegawatdaruratan obstetri akan meningkatkan pelaksanaan rujukan terencana lebih dari 6 kali $(\mathrm{OR}=6,12)$. Simpulan penelitian ini adalah faktor risiko kegawatdaruratan obstetri pada AGDO berhubungan dengan pelaksanaan rujukan dan peningkatan faktor risiko kegawatdaruratan obstetri akan meningkatkan pelaksanaan rujukan oleh bidan.
\end{abstract}

Kata kunci: Kegawatdaruratan obstetri, rujukan obstetri 


\title{
Association Risk Factors of Obstetric Emergency by Rochjati with Midwife Referral Implementation in Gambiran Hospital Kediri
}

\begin{abstract}
Obstetric emergencies is a major cause of maternal and perinatal mortality. Emergency obstetric according Rochjati divided into 3 groups of risk factors, namely APGO (there's Potential Distress Obstetrics), AGO (there's Intensive Care Obstetrics), and AGDO (there's Emergency Obstetrics). Various studies suggest that one of the effective management efforts on the implementation of the emergency obstetric referral. Appropriate referral and planned can save the mother and the newborn. This study aims to determine the relationship of risk factors for obstetric emergencies (APGO, AGO, and AGDO) and a reference implementation by midwives in hospitals Gambiran Kediri. Quantitative research design used a cross sectional approach implemented at January-February 2014, with the number sampling of 150 samples was done by consecutive sampling. Secondary data collection based report delivery room and hospital records period of January-December 2011. The results showed no significant differences in risk factors of obstetric emergencies on variable APGO and AGO between planned referral and late referral ( $p>0.05)$, but there was a significant differences were performed on variables AGDO between planned referral and late referral. The increased risk of obstetric emergencies will improve the implementation of the planned reference more than 6 times $(\mathrm{OR}=6.12)$. Based on these results it can be conclude that there was a risk factor for obstetric emergencies in AGDO the reference implementation and the increased risk of obstetric emergencies will improve the implementation of the referral by midwives.
\end{abstract}

Keywords: Obstetrics emergencies, obstetric referral

\section{Pendahuluan}

Angka Kematian Ibu (AKI) dan Angka Kematian Bayi ${ }^{1}$ di Indonesia masih cukup tinggi. AKI memberikan pengaruh yang besar pada dirinya, keluarga maupun masyarakat. Selain itu, akan meningkatkan kematian bayi. Laporan Kematian Ibu ${ }^{2}$ dalam Profil Kesehatan Provinsi Jawa Timur tahun 2012 menunjukkan penyebab terbesar kematian ibu secara langsung berturut-turut adalah preeklamsi berat/eklamsi sebesar 34,88\%; perdarahan 25,09\%; infeksi $4,98 \%$; dan penyebab yang lainnya $26,98 \%$. Kegawatdaruratan obstetri bertanggung jawab pada $70,6 \%$ kematian ibu dan $86 \%$ kematian perinatal. Selain itu, data menunjukkan AKI di Kabupaten/Kota Kediri pada tahun 2012 sebesar 182,77/100.000 KH. Angka kematian ibu di Kota Kediri pada tahun 2012 menempati peringkat kedua di Provinsi Jawa Timur, sedangkan AKB sebesar 27,79/1000 KH. ${ }^{1}$

Pemerintah telah berupaya untuk menurunkan AKI dengan berbagai hal yang terkait dengan kehamilan, persalinan, dan nifas. Salah satu upaya yang dilakukan dengan memberikan pelayanan kesehatan pada ibu hamil. $^{2}$ Upaya percepatan penurunan AKI berfokus pada deteksi dini, serta penanganan dan rujukan kehamilan/persalinan tinggi. ${ }^{3}$ Rujukan harus dilakukan dalam keadaan ibu dan anak masih baik agar tujuan sistem rujukan dapat tercapai. Oleh karena itu, rujukan yang dilakukan merupakan rujukan kehamilan bukan rujukan persalinan. Salah satu upaya untuk memudahkan pelaksanaan tersebut dengan Strategi Pendekatan Risiko (SPR). ${ }^{4}$ Pengelompokan faktor risiko menurut Rochjati terbagi dalam tiga kelompok; yaitu Ada Potensi Gawat Obstetri (APGO), Ada Gawat Obstetri ${ }^{3}$, dan Ada Gawat Darurat Obstetri (AGDO). ${ }^{5}$

Sejak tahun 1994, Dinas Kesehatan di seluruh kabupaten/kota Jawa Timur telah menerapkan sistem pelayanan kesehatan ibu melalui kegiatan rujukan terencana yang merupakan bagian program Kesehatan Ibu dan Anak (KIA) sebagai upaya pencegahan proaktif terhadap komplikasi persalinan serta kematian ibu dan bayi. ${ }^{5}$ Keberhasilan yang dicapai oleh provinsi Jawa Timur dalam penurunan AKI disebabkan kemampuan tenaga kesehatan dalam penerapan SPR dan sistem rujukan secara benar dengan memodifikasi faktor risiko dan sistem skoringnya. ${ }^{4}$ 


\section{Metode}

Penelitian ini merupakan penelitian kuantitatif dengan pendekatan cross sectional dengan jumlah sampel 150 pasien rujukan obstetri. Pengambilan sampel dilakukan dengan cara consecutive sampling. Kriteria inklusi pada penelitian ini adalah data pasien rujukan obstetri di RSUD Gambiran Kota Kediri, usia kehamilan $>24$ minggu, memiliki faktor risiko kegawatdaruratan obstetri, rujukan bidan yang bertugas di wilayah kerja Kota Kediri, dan memeroleh biaya pemerintah (Jamkesmas). Variabel faktor risiko kegawatdaruratan APGO, AGO, dan AGDO dengan alat ukur data rekam medik dan menggunakan angket penelitian. Selanjutnya, variabel pelaksanaan rujukan juga diukur dari data rekam medik berdasarkan gambaran klinis ibu hamil pada saat dirujuk ke rumah sakit. Perbedaan faktor risiko kegawatdaruratan pada APGO, AGO, dan AGDO antara rujukan terencana dan rujukan terlambat diuji dengan uji chi-kuadrat dan atau uji fisher. Hubungan peningkatan faktor risiko kegawatdaruratan dengan pelaksanaan rujukan dilakukan analisis dengan uji regresi logistik, sehingga kekuatan hubungan masing-masing variabel dapat diketahui. Penelitian dilaksanakan dari bulan Januari sampai dengan Februari 2014.

\section{Hasil}

Tabel 1 Distribusi Frekuensi Faktor Risiko Kegawatdaruratan Obstetri pada APGO, AGO, dan AGDO

\begin{tabular}{lcc}
\hline Kegawatdaruratan Obstetri & n & \% \\
\hline APGO & 41 & 27,3 \\
Tidak ada & 109 & 72,7 \\
Ada & & \\
AGO & 99 & 66,0 \\
Tidak ada & 51 & 34,0 \\
Ada & 121 & 80,7 \\
AGDO & 29 & 19,3 \\
Tidak Ada & 150 & 100,0 \\
Ada & \multicolumn{2}{l}{} \\
Total & \multicolumn{2}{l}{ kegawatdaruratan obstetri yang dimiliki. }
\end{tabular}

Berdasarkan tabel 1 diketahui sebagian besar responden tidak memiliki faktor risiko kegawatdaruratan obstetri. Frekuensi kegawatdaruratan obstetri sebagian besar adalah faktor risiko APGO yaitu 109 orang $(72,7 \%)$ dan sebagian kecil yaitu 29 orang (19,3\%) faktor risiko AGDO.

\section{Tabel 2 Distribusi Frekuensi Pelaksanaan Rujukan}

\begin{tabular}{lcc}
\hline Pelaksanaan Rujukan & $\mathbf{N}$ & \% \\
\hline Terencana & 135 & 90,0 \\
Terlambat & 15 & 10,0 \\
\hline Total & 150 & 100,0 \\
\hline
\end{tabular}

Berdasarkan tabel 2 diketahui bahwa sebagian besar responden yaitu 135 orang (90\%) dilakukan rujukan terencana dan sebagian kecil yaitu 15 orang (10\%) rujukan terlambat.

\section{Tabel 3 Perbedaan Faktor Risiko Kegawatdaruratan Obstetri pada APGO antara Rujukan Terencana dan Rujukan Terlambat}

\begin{tabular}{llccc}
\hline & & $\begin{array}{c}\text { Rujukan } \\
\text { Terencana }\end{array}$ & $\begin{array}{c}\text { Rujukan } \\
\text { Terlambat }\end{array}$ & Nilai p \\
\cline { 3 - 4 } & N & n & \\
\hline APGO & $\begin{array}{l}\text { Tidak } \\
\text { ada }\end{array}$ & 39 & 2 & 0,16 \\
& Ada & 96 & 13 & 5 \\
\hline Total & & 135 & 15 & \\
\hline
\end{tabular}

Keterangan: Nilai p berdasarkan Uji Eksak

Berdasarkan tabel 3 diketahui sebagian besar memiliki faktor risiko APGO dan dirujuk secara terencana yaitu 96 dari 135 orang (72\%). Hasil uji tidak terdapat perbedaan bermakna $(\mathrm{p}>0,05)$ pada faktor risiko APGO antara rujukan terencana dan rujukan terlambat.

\section{Tabel 4 Perbedaan Faktor Risiko Kegawatdaruratan Obstetri pada AGO antara Rujukan Terencana dan Rujukan Terlambat}

\begin{tabular}{lcccc}
\hline & & $\begin{array}{c}\text { Rujukan } \\
\text { Terencana }\end{array}$ & $\begin{array}{c}\text { Rujukan } \\
\text { Terlambat }\end{array}$ & $\begin{array}{c}\text { Nilai } \\
\text { p }\end{array}$ \\
\cline { 3 - 4 } & N & n & \\
\hline AGO & Tidak & 89 & 10 & 0,954 \\
& ada & 46 & 5 & \\
& Ada & & & \\
\hline Total & & 135 & 15 & \\
\hline Keterangan: nilai p berdasarkan uji chi-kuadrat &
\end{tabular}

Berdasarkan tabel 4 dapat diketahui sebagian besar tidak memiliki faktor risiko AGO dan dirujuk secara terencana yaitu 89 dari 135 
Fauzia Laili : Hubungan Faktor Risiko Kegawadaruratan Obstetri Menurut Rohjati Dengan Pelaksanaan Rujukan oleh Bidan di RSUD Gambiran Kediri

orang $(66 \%)$. Hasil uji tidak terdapat perbedaan bermakna $(p>0,05)$ pada faktor risiko AGO antara rujukan terencana dan rujukan terlambat.

Tabel 5 Perbedaan Faktor Risiko Kegawatdaruratan Obstetri pada AGDO antara Rujukan Terencana dan Rujukan Terlambat

\begin{tabular}{|c|c|c|c|}
\hline & $\begin{array}{c}\text { Rujukan } \\
\text { Terencana }\end{array}$ & $\begin{array}{c}\text { Rujukan } \\
\text { Terlambat }\end{array}$ & \multirow[t]{2}{*}{$\begin{array}{c}\text { Nilai } \\
\text { p }\end{array}$} \\
\hline & $\mathbf{n}$ & n & \\
\hline AGDO Tidak & 113 & 8 & 0,011 \\
\hline $\begin{array}{l}\text { ada } \\
\text { Ada }\end{array}$ & 22 & 7 & \\
\hline Total & 135 & 15 & \\
\hline
\end{tabular}

Keterangan: Nilai p berdasarkan uji Eksak Fisher

Berdasarkan Tabel 5, sebagian besar responden tidak memiliki faktor risiko AGDO dan dirujuk secara terencana yaitu 113 dari 135 orang $(84 \%)$. Hasil uji terdapat perbedaan bermakna $(p<0,05)$ pada faktor risiko AGDO antara rujukan terencana dan rujukan terlambat.

Tabel 6 Hubungan Peningkatan Faktor Risiko Kegawatdaruratan Obstetri dengan Pelaksanaan Rujukan

\begin{tabular}{|c|c|c|c|}
\hline Variabel & Koefisien & Nilai $p$ & $\begin{array}{l}\text { POR (IK } \\
95 \%)\end{array}$ \\
\hline APGO & 1,452 & 0,080 & $\begin{array}{c}4,270(0,841- \\
21,695)\end{array}$ \\
\hline AGDO & 1,812 & $0,003 *$ & $\begin{array}{c}6,122(1,879- \\
19,939)\end{array}$ \\
\hline Konstanta & $-3,894$ & & \\
\hline
\end{tabular}

Berdasarkan Tabel 6, nilai POR $=6,12$ pada variabel AGDO. Hal ini berarti bahwa variabel yang berpengaruh pada pelaksanaan rujukan yaitu faktor risiko kegawatdaruratan AGDO. Kekuatan hubungan variabel AGDO dengan pelaksanaan rujukan terencana hingga lebih dari 6 kali, hal ini berarti bahwa faktor risiko kegawatdaruratan pada AGDO berpeluang meningkatkan pelaksanaan rujukan hingga lebih dari 6 kali.

\section{Pembahasan}

Berdasarkan hasil penelitian di atas, menunjukkan hampir seluruh responden yang memiliki risiko kegawatdaruratan pada APGO, AGO, dan AGDO dirujuk secara terencana. Hal ini menunjukkan sistem rujukan di daerah Kota Kediri telah terlaksana dengan baik. Berdasarkan hasil wawancara, bidan menyatakan sistem rujukan telah diterapkan dengan baik. Terbukti dengan salah satu aturan atau kebijakan dinas kesehatan kota untuk ibu hamil yang dirujuk bidan ke rumah sakit, yaitu ibu hamil yang memiliki risiko kegawatdaruratan obstetri dan jumlah skor risiko $\geq 10$.

Hal ini sesuai dengan upaya pemerintah dalam menurunkan AKI dan AKB, yaitu pengembangan fasilitas kesehatan yang berjenjang dengan menentukan kebijakan yang berfokus pada penanganan ibu hamil yang memiliki komplikasi dan pencegahan terhadap tiga terlambat (pengambilan keputusan, transportasi ke pusat rujukan, dan penanganan yang adekuat di RS rujukan). ${ }^{4}$ Penelitian di Nigeria menunjukkan sistem rujukan obstetri yang baik akan meningkatkan pelayanan yang berkualitas sehingga kesehatan ibu hamil dan bersalin optimal. ${ }^{6}$ Rujukan harus dilakukan pada keadaan ibu dan anak masih baik dan rujukan yang dilakukan seharusnya pada saat kehamilan bukan saat persalinan sehingga tujuan sistem rujukan tercapai, ${ }^{4}$ sedangkan tujuan utama sistem rujukan obstetri yaitu memberikan pelayanan yang berkualitas dan sesuai dengan kebutuhan ibu hamil sehingga kesehatan ibu hamil dan bersalin mencapai tingkat optimal. ${ }^{6}$

Sistem rujukan obstetri merupakan salah satu elemen penting dalam kesuksesan program Safe Motherhood, apabila sistem rujukan telah terlaksana dengan baik maka angka kematian ibu di Indonesia juga menurun. ${ }^{7}$ Sesuai penyataan Adisasmito, bahwa sistem rujukan berperan penting dalam pencapaian sistem kesehatan, apabila sistem rujukan tersedia dengan baik dan terjangkau oleh masyarakat maka taraf kesehatan masyarakat akan meningkatkan. ${ }^{8}$

Berdasarkan beberapa pernyataan tersebut dapat disimpulkan bahwa sistem rujukan dapat tercapai apabila dilakukan rujukan terencana yaitu rujukan secara dini dan tepat waktu. Rujukan terencana merupakan upaya pencegahan secara proaktif terhadap komplikasi persalinan dan perencanaan persalinan yang aman. ${ }^{5} \mathrm{Hal}$ ini sesuai juga dengan beberapa penelitian lain yang menyatakan bahwa ibu hamil dengan komplikasi diperlukan pemantauan dan perawatan ke unit kesehatan yang lebih lengkap dan lebih baik, 
sehingga dapat disimpulkan bahwa rujukan obstetri perlu dilakukan pada ibu dengan komplikasi selama kehamilan agar tidak terjadi komplikasi yang lebih lanjut, baik pada ibu maupun bayinya. $4,5,9,10$

Hasil penelitian ini menunjukkan tidak terdapat perbedaan bermakna faktor risiko kegawatdaruratan pada APGO dan AGO yang dirujuk terencana dan terlambat dirujuk, namun terdapat perbedaan bermakna pada faktor risiko kegawatdaruratan AGDO antara rujukan terencana dan rujukan terlambat. Selain itu, peningkatan faktor risiko kegawatdarutan obstetri akan meningkatkan pelaksanaan rujukan hingga lebih dari enam kali.

Pelaksanaan rujukan sangat dibutuhkan untuk mengurangi kemungkinan komplikasi yang terkait dengan kehamilan agar memperoleh perawatan kesehatan yang lebih baik..$^{5,6,10}$ Menurut Rochjati, salah satu upaya untuk mencegah dan mengatasi masalah komplikasi obstetri dengan pelaksanaan rujukan terencana. ${ }^{5}$ Rujukan terencana merupakan salah satu upaya pencegahan proaktif terhadap komplikasi persalinan dan merupakan komponen perawatan prenatal yang dibutuhkan bagi ibu hamil dengan risiko. Selain itu, Yakoob dkk. juga menyatakan bidan terampil dapat mengelola kehamilan, persalinan, dan nifas termasuk mengidentifikasi, melaksanakan manajemen, dan rujukan dalam komplikasi. ${ }^{11}$

Hasil penelitian ini menunjukkan sebagian besar ibu yang dirujuk ke rumah sakit memiliki beberapa faktor risiko meliputi: usia $\geq 35$ tahun, kehamilan letak sungsang, dan hamil dengan komplikasi preeklamsi berat/eklamsi. Beberapa hasil penelitian menjelaskan bahwa semakin bertambah atau semakin tua usia ibu saat hamil akan meningkatkan risiko kematian. ${ }^{12-14}$ Komplikasi langsung penyebab kematian pada ibu salah satunya adalah kehamilan letak sungsang dan preeklamsi berat/eklamsi. Berdasarkan hasil penelitian dinyatakan kehamilan letak sungsang sangat memengaruhi kesejahteraan ibu dan bayi pada masa berikutnya. $^{15}$ Hasil penelitian lain juga menunjukkan preeklamsi berat/eklamsi merupakan salah satu komplikasi penyebab utama kesakitan dan kematian ibu. ${ }^{16,17}$

Berdasarkan keadaan tersebut, suatu tindakan segera diperlukan untuk menangani komplikasi obstetri sehingga kesakitan dan kematian dapat dihindari dan dicegah. Hal ini sependapat dengan pernyataan Wijayanegara dkk $^{18}$ yang menyatakan kegawatdaruratan obstetri membutuhkan tindakan yang cepat, tegas, dan efektif. Selain itu, menurut Rochjati ${ }^{5}$ juga dijelaskan upaya yang dapat dilakukan untuk mencegah komplikasi akibat keadaan tersebut adalah penanganan adekuat terhadap kondisi gawat darurat dengan pelaksanaan rujukan terencana.

Hasil penelitian juga menunjukkan ada beberapa responden yang memiliki faktor risiko kegawatdaruratan obstetri namun terlambat dirujuk. Menanggapi hal ini, bidan menyatakan rujukan terlambat yang dilakukan pada beberapa ibu hamil dengan faktor risiko karena ibu hamil tersebut datang ke bidan dengan kondisi usia kehamilan tua dan mendekati persalinan. Berdasarkan hal tersebut, rujukan terlambat pada penelitian ini kemungkinan disebabkan oleh kurangnya kesadaran pasien tentang tanda bahaya pada kehamilan dan pengambilan keputusan mendapatkan perawatan oleh tenaga kesehatan.

Hal ini sesuai dengan penelitian di Pakistan yang menunjukkan beberapa penyebab keterlambatan rujukan, yaitu kurangnya kesadaran tentang tanda bahaya obstetri sehingga terlambat dalam pengambilan keputusan mendapatkan perawatan medis untuk mengatasi komplikasi obstetri. ${ }^{19}$ Selain itu, menurut Rochjati $^{5}$ rujukan terencana merupakan salah satu komponen perawatan prenatal bagi ibu hamil dengan risiko sehingga dapat disimpulkan ibu hamil yang tidak memeriksakan diri selama kehamilan akan meningkatkan kemungkinan rujukan terlambat.

Hasil penelitian menunjukkan hampir seluruh responden dirujuk terencana. Hal ini dimungkinkan karena pada saat tersebut sedang dilaksanakan program Jaminan Persalinan (Jampersal). Hal ini didukung oleh hasil wawancara yang dilakukan pada beberapa bidan tentang penyebab ibu hamil dirujuk ke rumah sakit meskipun tidak memiliki faktor risiko kegawatdaruratan. Menanggapi hal ini, bidan menyatakan pelaksanaan rujukan ibu hamil ke rumah sakit tanpa memiliki faktor risiko kegawatdaruratan disebabkan oleh program Jampersal. Kompensasi dan lamanya waktu penerimaan kompensasi menjadi pertimbangan bidan merujuk ibu hamil ke rumah sakit. Sesuai dengan hasil penelitian yang menunjukkan pelaksanaan kebijakan program Jampersal 
Fauzia Laili : Hubungan Faktor Risiko Kegawadaruratan Obstetri Menurut Rohjati Dengan Pelaksanaan Rujukan oleh Bidan di RSUD Gambiran Kediri

berpengaruh positif dan bermakna pada kinerja bidan dalam meningkatkan akses ibu hamil menggunakan fasilitas kesehatan. ${ }^{20}$

Penelitian ini menunjukkan peningkatan faktor risiko kegawatdaruratan akan meningkatkan pelaksanaan rujukan hingga $>6$ kali. Beberapa penelitian menunjukkan kegawatdaruratan obstetri membutuhkan tindakan yang cepat, tegas, dan efektif untuk mencegah komplikasi akibat keadaan tersebut dengan pelaksanaan rujukan yang terencana, ${ }^{5,18}$ keadaan gawat darurat pada kehamilan merupakan penyebab utama terjadinya kesakitan dan kematian ibu sehingga diperlukan tindakan segera untuk menanganinya yaitu dengan pelaksanaan rujukan. ${ }^{16}$

\section{Simpulan}

Berdasarkan hasil penelitian menunjukkan sebagian besar responden dirujuk terencana karena sistem rujukan telah terlaksana dengan baik. Sebagian besar responden yang dirujuk ke rumah sakit karena memiliki faktor risiko pada kegawatdaruratan obstetri meliputi: usia $\geq 35$ tahun pada saat hamil, kehamilan letak sungsang, dan hamil dengan komplikasi preeklamsi berat/eklamsi. Hasil penelitian juga menunjukkan tidak terdapat perbedaan bermakna faktor risiko kegawatdaruratan obstetri pada APGO dan AGO, namun berbeda bermakna faktor risiko kegawatdaruratan pada AGDO antara rujukan terencana dan rujukan terlambat. Selain itu, peningkatan faktor risiko kegawatdaruratan pada AGDO juga akan meningkatkan pelaksanaan rujukan hingga lebih dari 6 kali.

\section{Daftar Pustaka}

1. Dinas Kesehatan Propinsi Jawa Timur. Profil Kesehatan Provinsi Jawa Timur 2012. Surabaya: Dinkes Prov. Jatim. 2013.

2. Kementerian Kesehatan RI. Profil Kesehatan Indonesia 2010. Jakarta: Kem Kes RI. 2010.

3. Collender G, Gabrysch S, Campbell OMR. Reducing maternal mortality: better monitoring indicators, and benchmarks needed to improve emergency obstetric care. Trop Med Intern Health. 2012; 17(6):694-6.

4. Manuaba IBG, Rochjati P, Martaadisoebrata D. Bunga rampai obstetri dan ginekologi sosial. Jakarta: PT. Bina Pustaka Sarwono Prawirohardjo; 2011.

5. Rochjati P. Rujukan terencana dalam sistem rujukan paripurna terpadu kabupaten/kota. Surabaya: Airlangga University Press; 2004.
6. Bossyns P, Abache R, Abdoulaye MS, Miye M, Depoorter AM, Lerberge WV. Monitoring the referral system through benchmarking in rural Niger: An evaluation of functional relation between health centers and the district hospital. BMC Health Service Research. 2006; 6(51):1-7.

7. Murray SF, Pearson SC. Maternity referral systems in developing countries: Current knowledge and future research needs. Social Scien Med J. 2006; 62:2205-9.

8. Adisasmito W. Sistem kesehatan. Edisi ke-4. Jakarta: Rajawali Pers; 2012.

9. Al JF. Grandemultiparity: a potential risk factor for adverse pregnancy outcomes. J Reprod Med. 2012; 57(1-2):53-7.

10. Afolabi AF, Adeyemi AS. Grand-multiparity: is it still an obstetric risk?. OJOG. 2013; 3:411-5.

11. Yakoob MY, Ali MA, Ali MU, Imdad A, Lawn JE, Van Den Broek, dkk. The effect of providing skilled birth attendance and emergency obstetric care in preventing stillbirths. BMC Public Health. 2011; 11(57):1-8.

12. Pembe AB, Carlstedt A, Urassa DP, Lindmark G, Nystrom L, Darj E. Effectiveness of maternal referral system in a rural setting: a case study from Rufiji district, Tanzania. BMC Health Services Research. 2010; 10(326):1-9.

13. Surita FG, Solvia JLP, Cecatti JG, Parpiinelli MA, Haddad SM, Costa ML, dkk. Severe maternal morbidity and maternal near miss in the extremes of reproductive age: results from a national cross- sectional multicenter study. BMC Pregnancy and Chidlbirth. 2014; 14(77):118 .

14. Lampinen R, Vehvilainen-Julkunen K, Kankkunen P. A Review of pregnancy in women over 35 years of age. Open Nursing J. 2009; 3:33-8.

15. Sorbye IK, Vangen S, Oneko O, Sundby J, Bergsjo P. Caesarean section among referred and selfreferred birthing women: a cohort study from a tertiary hospital, northeastern Tanzania. BMC Pregnancy and Childbirth 2011; 11(55):1-11.

16. Alladin AA, Harrison M. Preeklamsi: systemic endothelial damage leading to increased activation of the blood coagulation cascade. J Biotech Research. 2012; 4:26-43.

17. Belfort MA, Dildy GA, Herbst MA, Meyers JA, and Hankins GD. Maternal death in the $21^{\text {st }}$ century: causes, prevention, and relationship to cesarean delivery. Am J Obstet Gynecol. 2008; 199(1):1-11

18. Wijayanegara H. Epidemiologi kegawatdaruratan obstetric. Dalam: Krisnadi SR, Anwar AD, Alamsyah M, penyunting. Obstetri emergensi. Jakarta: Sagung Seto. 2012.

19. Midhet F, Stan B. Impact of community-based interventions on maternal and neonatal health indicators: Results from a community randomized trial in rural Balochistan, Pakistan. Reproductive Health J. 2010; 7(30):1-10.

20. Wildan M, Prijatni I, Martini L. Perbedaan jumlah rujukan penapisan sebelum dan sesudah program jaminan persalinan (Jampersal) di RS. Dr. Haryoto Lumajang. Seminar Nasional Jampersal; 2011; Jember: Universitas Jember; 2011. 
1. Namazi M, Akbari SAA, Mojab F, Talebi A, Majd HA, jannesari S. Aromatherapy with citrus Aurantium Oil Oval Anxiety During the Stage Of Labor. Iran Red Crescent Med J. 2014;16(6):11screen.

2. mandal BK, Wilkins EG, Dunbar EM, White RTM. Penyakit Infeksi. 2 ed. jakarta: Erlangga; 2006.

3. Behruzi R, Haterm M, Goulet L, Li M, Misago C. Facilitators and barriers in the humanization of

childbirth practice in Japan. BMC Pregnancy Childbirth. 2010;10(25). 